\title{
Plasma D-lactate Levels in Necrotizing Enterocolitis in Premature Infants
}

\author{
Guofeng Lei, Junping Zhang, ${ }^{1, *}$ Xiaobing Wang, and Meiling Chen ${ }^{1}$ \\ ${ }^{1}$ Department of Neonatal Intensive Care Unit, Sanmenxia Central Hospital, Sanmenxia, China \\ ${ }^{*}$ Corresponding author: Junping Zhang, Department of Neonatal Intensive Care Unit, Sanmenxia Central Hospital, Sanmenxia, Henan 4720 00, China. Tel: +86-15036469906, Fax: \\ +86-0398933151, E-mail: leiguofeng1981@sina.com
}

Received 2015 October 18; Revised 2015 December 5; Accepted 2015 December 16.

\begin{abstract}
Background: D-Lactate is normally present in the blood of humans at nanomolar concentrations due to methylglyoxal metabolism; millimolar D-lactate concentrations can arise due to excess gastrointestinal microbial production.

Objectives: To examine the levels of plasma D-lactate in the necrotizing enterocolitis in premature infants.

Patients and Methods: 128 premature infants were divided into control (group I, n = 69), feeding intolerance (group II, n = 42) and NEC (group III, $n=27$ ) groups. Plasma D-lactate levels were measured at the onset of feeding intolerance or NEC and at weeks 2-3 in control infants (group I) by ELISA. Data were analyzed using descriptive statistics, non-parametric tests and Student's t-test.

Results: In groups I, II, III, median birth weights were $1845.7 \pm 267.5 \mathrm{~g}, 1913.1 \pm 306.5 \mathrm{~g}$, and $1898.4 \pm 285.3 \mathrm{~g}$, median gestational ages were $34.3 \pm 1.7$ weeks, $33.9 \pm 2.2$ weeks and $35.1 \pm 2.6$ weeks, ages of sampling were $12.3 \pm 2.9$ days, $14.6 \pm 3.7$ days and $15.1 \pm 1.8$ days, respectively. The differences of median birth weights, median gestational ages and ages of sampling were not statistically significant $(P>0.05)$. The plasma D-lactate levels in groups I, II, III were $3.6 \pm 1.9 \mu \mathrm{g} / \mathrm{mL}, 12.7 \pm 8.3 \mu \mathrm{g} / \mathrm{mL}$, and $35.4 \pm 29.1 \mu \mathrm{g} / \mathrm{mL}$, respectively, group III had higher plasma D-lactate level than groups I, II, and the difference among these groups was significant $\left(x^{2}=21.6, \mathrm{P}<0.01\right)$.

Conclusions: Plasma D-lactate significantly increased early in NEC. Plasma D-lactate levels were associated with extensive disease in NEC infants. Therefore, it could be used as a diagnosis indicator in the early stage of NEC.
\end{abstract}

Keywords: Premature, Newborn, Plasma D-Lactate, Necrotizing Enterocolitis

\section{Background}

D-Lactate is normally present in the blood of humans at nanomolar concentrations due to methylglyoxal metabolism; millimolar D-lactate concentrations can arise due to excess gastrointestinal microbial production. Grain overload in ruminants, short-bowel syndrome in humans, and diarrhea in calves can all result in profound D-lactic acidemia, with remarkably similar neurological manifestations. In the past, D-lactate was thought to be excreted mainly in the urine, and metabolized slowly by the enzyme D- $\alpha$-hydroxy acid dehydrogenase. More recent studies reported that mammals have a relatively high capacity for D-lactate metabolism and identified a putative mammalian D-lactate dehydrogenase. A growing body of literature is also emerging describing subclinical elevation of D-lactate as an indicator of sepsis and trauma especially in intestinal ischemia $(1,2)$. Garcia et al. found that urinary D-lactate increased in infants with NEC and demonstrated the increased enteric bacterial activity in NEC (3), but no plasma D-lactate test is available for neonatal necrotizing enterocolitis.

\section{Objectives}

Our study aimed to determine whether there was a sig- nificant difference of plasma D-lactate levels between NEC patients and age-matched controls.

\section{Patients and Methods}

\subsection{Patients}

Three groups of neonates treated in the neonatal intensive care unit (NICU) between May 2009 and June 2014 were enrolled in a prospective, ethically approved observational cohort study. This study was approved by the ethics committee of our institution. Controls (group I) were defined as premature infants ( $\leq 37$ completed weeks) admitted to NICU without NEC, sepsis or septic shock, systemic inflammatory response syndrome, or an inborn error of metabolism. Infants with congenital anomalies or who had recent surgery ( $<1$ week) were excluded from the study. Feeding intolerance (group II) was defined as persistent gastric aspirates $>50 \%$ of the fed volume with or without abdominal distension in the absence of culture-proven sepsis or radiological evidence of NEC (Bell's stage I NEC). Group III included infants with proven NEC (Bell's stage II and III). Data related to antenatal, perinatal and postnatal period were collected, includ-

Copyright (C) 2016, Growth \& Development Research Center. This is an open-access article distributed under the terms of the Creative Commons Attribution-NonCommercial 4.0 International License (http://creativecommons.org/licenses/by-nc/4.0/) which permits copy and redistribute the material just in noncommercial usages, provided the original work is properly cited. 
ing birth weight, gestational age and Apgar score. Plasma D-lactate level was determined within 24 hours of onset of symptoms in the subjects of each group. The parents/ guardians of patients and controls signed an informed consent form. The study groups consisted of neonates with a history of feeding intolerance or NEC as per Bell's staging II and III and who had long-term follow-up data available. All groups were age- and weight-matched.

\subsection{Plasma D-Lactate Quantification}

Blood was sampled by venipuncture and the serum harvested after centrifugation was stored at $-20^{\circ} \mathrm{C}$. Plasma D-lactate concentration was quantified using a commercially available enzyme-coupled UV-spectrophotometry (the test kit was produced in the Shanghai Baoman biotechnology co., Ltd., Shanghai, China). After adding $40 \mathrm{uL}$ sample diluent to $10 \mathrm{uL}$ of each sample in the 96-well plate; and $100 \mathrm{uL}$ of HRP-conjugate reagent to each well, it was covered with an adhesive strip and incubated for 60 minutes at $37^{\circ} \mathrm{C}$. After three washings, any remaining wash solution was removed by aspirating or decanting and.chromogen solution A $50 \mathrm{uL}$ and chromogen solution B $50 \mathrm{uL}$ was added to each well. Finally, $50 \mathrm{uL}$ stop solution was added to each well. Optical density (OD) at $450 \mathrm{~nm}$ was read using a microtiter plate reader within 15 minutes. Plasma D-lactate levels were quantified by comparison with a set of predetermined standards. All standards and samples were added in duplicate.

\subsection{Statistical Analysis}

SPSS 13.0 software was used for statistical analysis. All data were presented as mean \pm SD. Statistical differences between two groups were evaluated using unpaired Student's t-test or Kruskal-Wallis test. Differences were considered statistically significant at $\mathrm{P}<0.05$.

\section{Results}

\subsection{Demographic Characteristics}

128 subjects were included in our study, 80 were male and 48 were female, who were divided into three groups: group I $(n=69)$, group II $(n=42)$ and group III $(n=27)$. Median birth weights in groups I, II and III were 1845.7 $\pm 267.5,1913.1 \pm 306.5$, and $1898.4 \pm 285.3$ g, median gestational ages were $34.3 \pm 1.7,33.9 \pm 2.2$ and $35.1 \pm 2.6$ weeks, age of sampling were $12.3 \pm 2.9,14.6 \pm 3.7$, and $15.1 \pm 1.8$ days, respectively. The differences of sex, gestational age and birth weight between group I and II or III were not statistically significant $(\mathrm{P}>0.05)$ (Table 1$)$.

\subsection{Plasma D-Lactate Levels}

Plasma D-lactate levels were measured in all 128 infants. The plasma D-lactate levels in groups I, II and III were 3.6 $\pm 1.9 \mathrm{ug} / \mathrm{mL}, 12.7 \pm 8.3 \mathrm{ug} / \mathrm{mL}$, and $35.4 \pm 29.1 \mathrm{ug} / \mathrm{mL}$ (Figure
1). Infants in group III had highest level of D-lactate compared with group II and I using Kruskal-Wallis test.

\begin{tabular}{|c|c|c|c|}
\hline & Group I $(n=69)$ & Group II $(n=42)$ & Group III $(\mathbf{n}=\mathbf{2 7})$ \\
\hline \multicolumn{4}{|l|}{ Gender } \\
\hline Male & 39 & 25 & 16 \\
\hline Female & 30 & 17 & 11 \\
\hline $\begin{array}{l}\text { Gestational age, } \\
\text { corrected, w }\end{array}$ & $34.3 \pm 1.7$ & $33.9 \pm 2.2$ & $35.1 \pm 2.3$ \\
\hline Age of sampling, $d$ & $12.3 \pm 2.9$ & $14.6 \pm 3.7$ & $15.1 \pm 1.8$ \\
\hline Birth weight, $g$ & $1845.7 \pm 267.5$ & $1913.1 \pm 306.5$ & $1898.4 \pm 285.3$ \\
\hline $\begin{array}{l}\text { Plasma D-lactate } \\
\text { levels, ug/mL }\end{array}$ & $3.6 \pm 1.9$ & $12.7 \pm 8.3^{b}$ & $35.4 \pm 29.1^{b}$ \\
\hline
\end{tabular}

Figure 1. The plasma D-lactate Concentrations Among Three Groups

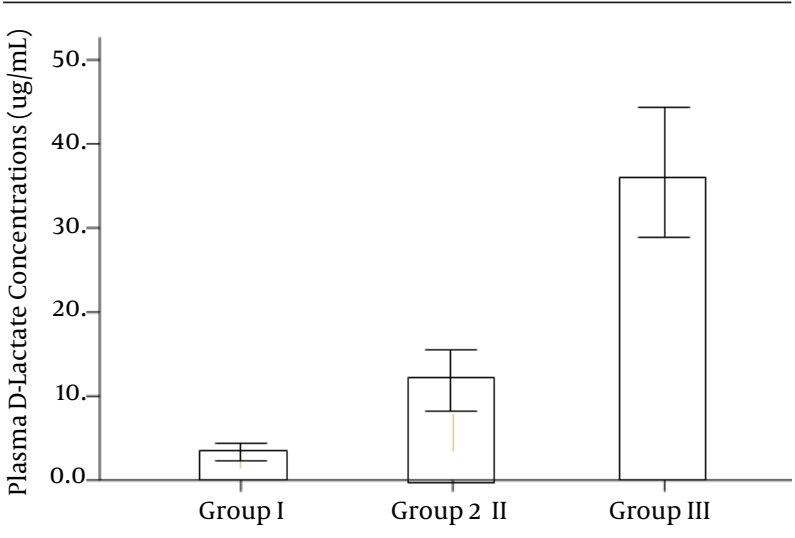

The feeding intolerance group had higher plasma D-lactate levels compared with contorl group. NEC group had highest Plasma D-lactate levels.

\section{Discussion}

Necrotizing enterocolitis (NEC) continues to be a potentially devastating complication for the extremely low birth weight (ELBW) premature infant $(4,5)$. Although the survival rates of some premature populations have been reported to be $80 \%$, ELBW patients fare much worse with survival ranging from $41 \%$ to $55 \%$ (4-6).

Currently, the diagnosis of NEC is based on clinical and radiographic findings. Once patients are diagnosed with definitive NEC (Bell's stage 2), significant intestinal damage is likely to occur. Therefore, it is possible that earlier detection of intestinal injury and appropriate treatment might prevent the progression of the disease $(7,8)$. Despite rapid modern medical advances, the etiology remains elusive, and morbidity and mortality is unacceptably high, with as much as $10 \%-30 \%$ of affected infants succumbing to the disease $(9,10)$. Although the pathophysiology is incompletely understood, it is known that prematurity, formula feeding, intestinal ischemia, re- 
perfusion, and bacterial colonization are important risk factors $(11,12)$. Based on extensive laboratory and human investigation, it appeared that acute intestinal ischemia, reperfusion and bacterial colonization were associated with failure of the mucosal barrier, and thus, resulting in increased plasma D-lactate levels in both portal and systemic blood. D-Lactate is normally produced in the fermentative organs of the gastrointestinal tract (rumen, cecum, colon), mainly by lactobacilli and bifidobacteria. Under normal circumstances, lactate does not pose an acid-base threat because it is converted by other microbes to acetate and other SCFAs (13). Nielsen C, et al. found that D-lactate measured in higher concentrations arises from bacterial fermentation in the gastrointestinal tract. Permeable intestinal wall is an early consequence of intestinal ischemia, which allows D-lactate to enter the portal circulation (14).

In our study, infants in feeding intolerance group had higher plasma D-lactate levels, compared with control group. NEC group had the highest plasma D-lactate levels. Our study suggests that elevated plasma D-lactate levels can occur in early NEC (Bell's stage 1). Plasma D-lactate level was associated with extensive disease in infants with NEC.

In conclusion, this study supports the use of plasma Dlactate levels as a marker of intestinal injury in neonatal necrotizing enterocolitis, where it predicts the extent of intestinal involvement. It also supports that the D-lactate may also serve as an early biomarkers for the diagnosis of infants with NEC. The identification of intestinal ischemia before intestinal necrosis and perforation occur could facilitate early diagnosis and therapeutical intervention, which could lead to improved outcome in these delicate infants. Other markers can be difficult to interpret, and future studies should aim to find the normal levels of plasma D-lactate in neonates and adults to assist clinicians in the diagnosis of NEC, allowing earlier therapeutic intervention with improved survival rate.

\section{References}

1. Ewaschuk JB, Naylor JM, Zello GA. D-Lactate in human and ruminant metabolism. J Nutr. 2005;7:1619-25.

2. Henry H, Marmy Conus N, Steenhout P, Beguin A, Boulat O. Sen- sitive determination of D-lactic acid and L-lactic acid in urine by high-performance liquid chromatography-tandem mass spectrometry. Biomed Chromatogr. 2012;26(4):425-8. doi: 10.1002| bmc.1681. [PubMed: 21842515]

3. Garcia J, Smith FR, Cucinell SA. Urinary D-lactate excretion in infants with necrotizing enterocolitis. JPediatr.1984;104(2):268-70. [PubMed: 6694024]

4. Morrow AL, Lagomarcino AJ, Schibler KR, Taft DH, Yu Z, Wang B, et al. Early microbial and metabolomic signatures predict later onset of necrotizing enterocolitis in preterm infants. Microbiome. 2013;1(1):13. doi:10.1186/2049-2618-1-13. [PubMed: 24450576]

5. Tommiska V, Heinonen K, Ikonen S, Kero P, Pokela ML, Renlund $\mathrm{M}$, et al. A national short-term follow-Up study of extremely low birth weight infants born in Finland in 1996-1997. Pediatrics. 2001;107(1):E2. [PubMed: 11134466]

6. Elfvin A, Dinsdale E, Wales PW, Moore AM. Low birthweight, gestational age, need for surgical intervention and gram-negative bacteraemia predict intestinal failure following necrotising enterocolitis. Acta Paediatr. 2015;104(8):771-6. doi: 10.1111/apa.12997. [PubMed: 25762289]

7. Dimmitt RA, Meier AH, Skarsgard ED, Halamek LP, Smith BM, Moss RL. Salvage laparotomy for failure of peritoneal drainage in necrotizing enterocolitis in infants with extremely low birth weight. J Pediatr Surg. 2000;35(6):856-9. doi: 10.1053/ jpsu.2000.6865. [PubMed:10873026]

8. Morini F, di Crosta I, Ronchetti MP, Dituri F, Nahom A, Corchia $\mathrm{C}$, et al. Lactate dehydrogenase activity is increased in plasma of infants with advanced necrotizing enterocolitis. Pediatr Surg Int. 2008;24(6):705-9. doi: 10.1007/s00383-008-2156-2. [PubMed: 18414875]

9. Ng PC, Li K, Chui KM, Leung TF, Wong RP, Chu WC, et al. IP-10 is an early diagnostic marker for identification of late-onset bacterial infection in preterm infants. Pediatr Res. 2007;61(1):93-8. doi: 10.1203/01.pdr.000 0250207.95723.96. [PubMed:17211148]

10. Abrahamsson TR, Rautava S, Moore AM, Neu J, Sherman PM. The time for a confirmative necrotizing enterocolitis probiotics prevention trial in the extremely low birth weight infant in North America is now! JPediatr. 2014;165(2):389-94. doi:10.1016/j. jpeds.2014.05.012. [PubMed: 24948349]

11. Frost BL, Jilling T, Caplan MS. The importance of pro-inflammatory signaling in neonatal necrotizing enterocolitis. Semin Perinatol. 2008;32(2):100-6. doi: 10.1053/j.semperi.2008.01.001. [PubMed:18346533]

12. Bizzarro MJ, Ehrenkranz RA, Gallagher PG. Concurrent bloodstream infections in infants with necrotizing enterocolitis. JPediatr. 2014;164(1):61-6. doi: 10.1016/j.jpeds.2013.09.020. [PubMed: 24139563]

13. Ng PC. Biomarkers of necrotising enterocolitis. Semin Feta Neonatal Med. 2014;19(1):33-8. doi: 10.1016/j.siny.2013.09.002. [PubMed: 24080072]

14. Nielsen C, Lindholt JS, Erlandsen EJ, Mortensen FV. d-lactate as a marker of venous-induced intestinal ischemia: an experimental study in pigs. Int J Surg. 2011;9(5):428-32. doi: 10.1016/j. ijsu.2011.04.004. [PubMed: 21530695] 